University of Northern lowa

UNI ScholarWorks

$7-2006$

\title{
An Analysis of the Impact of Federated Search Products on Library Instruction Using the ACRL Standards
}

Christopher N. Cox

University of Northern lowa

Let us know how access to this document benefits you

Copyright @ 2006 The John Hopkins University Press. The copyright holder has granted permission for posting.

Follow this and additional works at: https://scholarworks.uni.edu/lib_facpub

Part of the Library and Information Science Commons

\section{Recommended Citation}

Cox, Christopher N., "An Analysis of the Impact of Federated Search Products on Library Instruction Using the ACRL Standards" (2006). Rod Library Faculty Publications. 4.

https://scholarworks.uni.edu/lib_facpub/4

This Article is brought to you for free and open access by the Rod Library at UNI ScholarWorks. It has been accepted for inclusion in Rod Library Faculty Publications by an authorized administrator of UNI ScholarWorks. For more information, please contact scholarworks@uni.edu. 


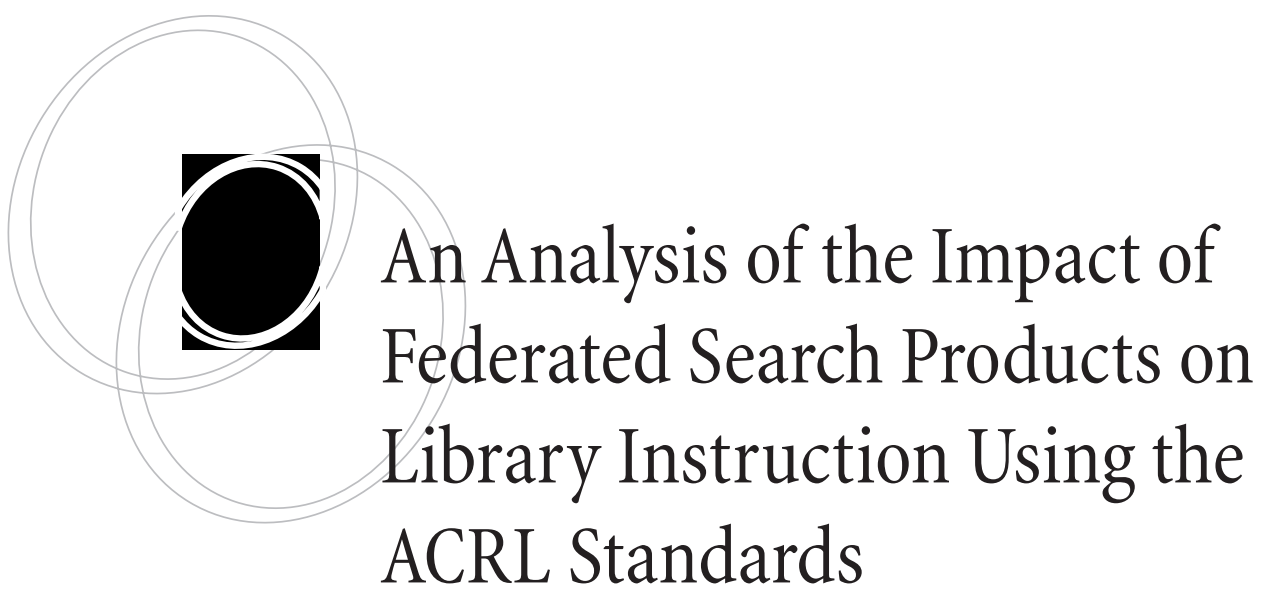

Christopher Cox

abstract: Federated search products are becoming more and more prevalent in academic libraries. What are the implications of this phenomenon for instruction librarians? An analysis of federated search products using the "Information Literacy Competency Standards for Higher Education" and a thorough review of the literature offer insight concerning whether these tools will have an impact on student information literacy and, in turn, what we emphasize in the classroom.

\section{Introduction}

1 ederated search products are becoming more and more prevalent in academic libraries. The literature is filled with articles debating the pros and cons of such tools, and concerns have been raised over whether they may have a negative impact on student information literacy. What are the implications of this phenomenon for instruction librarians? Will federated search products change the way we teach? What is the most effective way of introducing them into the curricula? An analysis of federated search products using the "Information Literacy Competency Standards for Higher Education" will offer insight concerning whether these tools will have an impact upon student information literacy and, in turn, what we emphasize in the classroom. ${ }^{1}$

\section{What is Federated Searching?}

Federated searching_-also known as metasearching, broadcast searching, or cross searching-allows users to simultaneously search multiple library databases, catalogs, and other collections via one common interface. There are a variety of products on the 
market, including Endeavor's ENCompass, WebFeat's Prism, and Ex Libris' MetaLib, which the University of Wisconsin-Eau Claire has implemented. These products are configurable so that students "will either see a single search box that defaults to a designated group of databases or will see the list of databases grouped into subjects." ${ }^{2}$ Students can then choose to search an entire subject category or specific databases within it. When search terms are entered, the software "transforms the query into appropriate syntax which can be understood by members of the group of resources and broadcasts it, merging the collected results and presenting them in a succinct and unified format devoid of duplication." ${ }^{3}$ The software also has a variety of personalization features that allow students to log in and save their search histories, create personal database lists, set up search alerts, and save citations for later viewing.

\section{Why Did Federated Search Tools Develop?}

Several factors influenced the development of federated searching products. The seemingly limitless number of digital library resources and databases that currently exist have become increasingly unwieldy for students, not to mention librarians. ${ }^{4}$ Students are expected to learn the names of these resources and what they include, along with their various interfaces and log-ins. ${ }^{5}$ Our current long lists of databases and the difficulty in navigating our Web sites have caused students equal concern. According to one student, "The whole point of the library is to have information that can be accessed EASILY and used for one's [own] uses. When that information is there, however, it is too difficult to get it. ...What good does it do?" 6

Our previous response has been to instruct students in finding the appropriate tools and utilizing them effectively. Countless studies have shown, however, that students prefer not to be taught. ${ }^{7}$ Roy Tennant, an outspoken advocate for federated search products, believes that "only librarians like to search; everyone else likes to find."

Students have responded by going to Google. In 2002, OCLC reported that 42 percent of students surveyed used search engines like Google for every assignment, whereas only 11 percent used the campus library Web site. ${ }^{9}$ Students prefer Google's simplicity, the single search box, the lack of decisions to be made, the full text, and the "good enough" results. ${ }^{10}$ They are pressed for time and see Google and the Internet as "the easiest, least painful way to complete a research project in a timely and satisfactory fashion."11

Google has changed the expectations of users and become serious competition for libraries. Librarians have grown more and more concerned about students' penchant for the Internet while ignoring the resources we spend millions of dollars collecting. ${ }^{12}$ Ed Tallent sums the situation up succinctly:

Students do not know what resources we have, have little interest in learning about alternative titles, do not search resources effectively, feel overwhelmed by the amount of information available, lack the time and inclination to learn more, and assume we do not have titles and formats that we have collected for years. ${ }^{13}$

In reaction to the competition, librarians have called for the development of Googlelike tools. Wendi Arant and Leila Payne discuss the need for a common user interface to all library resources. ${ }^{14}$ At times, the successful development of such tools is seen as in 
opposition to information literacy instruction. Judy Luther states that "library services that require training...undermine the advantages of licensing electronic content." 15 Stanley Wilder, in "Information Literacy Makes All the Wrong Assumptions," takes the argument one step further. Rather than "teach students the names of databases, the subjects and titles they include, and their unique protocols," he suggests that libraries "create systems that eliminate the need for instruction."16

\section{Federated Search Products and Information Literacy}

Discussion of federated search products in relation to information literacy has been fairly limited. Most writers fall on one side or the other of the current debate between those who favor federated search tools (Googlizers) and those in opposition to them (Resistors). Googlizers believe that students and libraries will benefit from offering the "Google experience," while Resistors argue student information literacy will pay the price for "dumbed down" interfaces that offer fewer choices and "good enough" results. ${ }^{17}$ William Frost views federated searching as "a way of avoiding the learning process" and suggests that it will have a negative impact on student learning since it allows students to avoid selecting the most appropriate research tool and does not promote sophisticated searching. ${ }^{18}$ Steven Bell claims that increasing students' dependence on search tools may "do even more to erode our profession's tradition of teaching those skills that enable researchers to do better than just good enough." ${ }^{19}$ Devin Zimmerman, on the other hand, sees federated searching products as good starting places for research, tools that "will compel us to recognize and create opportunities to help patrons advance their skills beyond the basics." 20

Only John Terrell and Lucy McCaskie attempt to directly address the impact federated searching products will have on student information literacy and lifelong learning. Terrell, in a paper based on his 2004 Lifelong Learning Conference presentation, examines federated searching in light of the Australian and New Zealand Institute for Information Literacy (ANZIIL) Framework. He questions the quality of the information these products contain and notes that students (1) may not know what databases they are searching and (2) may not utilize adequate search strategies. In contradiction to Luther and Wilder, Terrell believes that libraries that introduce federated search will still need to devote time to information literacy instruction. ${ }^{21}$ McCaskie comes to the same conclusion. She uses a qualitative research approach, conducting interviews both in person and via e-mail with librarians at institutions that have implemented federated search products, in an attempt to conclude if there have been any changes in information literacy instruction and whether the tool has had any impact on student information literacy. Librarians reported increased use of databases, concerns about the quality of results produced, and a need for information literacy instruction for students. In McCaskie's words, these tools "cannot prevent users from becoming information literate but by using information literacy skills users can make better use of these tools." 22 The following analysis of the "Information Literacy Competency Standards" builds upon Terrell's and McCaskie's research. 


\section{Analysis of the Information Competency Standards}

\section{Standard One}

Standard one states: "The information literate student determines the nature and extent of the information needed." ${ }^{23}$ Performance indicators include the ability to define and articulate the need for information and identify a variety of types and formats of potential sources of information. Having witnessed students performing Internet searches, we know that students in the beginning stages of their research tend to search first and ask questions later. As Tallent puts it, students "dive in, search and then react." ${ }^{24}$ Searching is seen as integral to the research discovery process. Carol Kuhlthau identifies six stages of this process. The first four-initiation (recognizing the information need), selection (identification), exploration (general investigation), and formulation (focusing the topic) — are all associated with standard one, performance indicator 1 . When identifying tasks appropriate to each of the six stages, Kuhlthau suggests students not gather information until stage five-collection. Seemingly ignoring the progression Kuhlthau set out, most participants limited their responses to "gather" or "complete"; and gathering information was listed as the main task under each of the first four stages. ${ }^{25}$

Students' desire to search first may be beneficial when using federated searching products. A relatively simple federated search can offer students a broad overview of their topics, allowing them to see overlaps between disciplines and offering them sources that may assist them in achieving a more manageable research focus. One might see this as the equivalent of reading an encyclopedia article to increase familiarity with a topic. There are consequences, however, to moving directly to the search process. Due to the breadth of resources that are included in a typical federated search, students who have not adequately developed their research

Students' desire to search first may be beneficial when using federated searching products. questions or have not thought enough about search terms and related concepts may risk returning too many results, possibly resulting in information overload and stress associated with their choice of topic and the research process in general. ${ }^{26}$

Librarians often encourage students to consider what information sources might include information on their topics. Based on their research question-its currency and its scope-students are asked to determine whether the answer may be found in a newspaper, peer-reviewed journal, directory, statistical database, or perhaps even on a Web site. Federated searching reduces the need for students to think about this. As Terrell points out, while federated searching products have the potential "to increase the range of sources used, by bundling the sources together it tends to inhibit the person's ability to distinguish between those sources and to recognize their unique characteristics." ${ }^{27}$ Students who have determined the best sources of information on their topics will have a difficult time narrowing their searches to just those sources. A typical federated search might return information from sources such as books, videos, magazines, peer-reviewed journals, images, archival materials, and so on. Students will be reliant on the citation information provided by the federated search product for each source to determine not only its relevancy to their research but also just what type of source 
it is. Students may also mistakenly assume that the federated searching product they are using encompasses all the library's sources, causing them to overlook potentially valuable sources that are not electronically available or which may not be as thoroughly indexed. Students, after all, are encouraged to "identify the value and difference of potential resources in a variety of formats," not just those that are electronically available or that can be simultaneously searched. ${ }^{28}$

\section{Standard Two}

Standard two concerns a student's ability to access needed information effectively and efficiently. The selection of the most appropriate investigative methods or information retrieval systems, construction and implementation of effectively designed search strategies, and retrieval of information online or in person are all indicators of satisfactory achievement.

Performance indicator 1: The information literate student selects the most appropriate investigative methods or information retrieval systems for accessing the needed information.

One of the most difficult tasks for the undergraduate researcher is choosing which database to search..$^{29}$ In order to determine the most appropriate resource for their research topics, students previously needed to ask a reference librarian for assistance. However, more often than not they turn to Google, ask the advice of friends, or rely on a database, which, while not necessarily appropriate to their current information need, has offered satisfactory results in the past. ${ }^{30}$

Federated search products are often seen as the answer to this problem. Tallent reports that Boston College students "readily admitted to not searching many databases and said they would broaden their choices if they could do the search simultaneously." ${ }^{31}$ Conducting a federated search reduces the need for students to know just what databases are most appropriate for a particular topic. They can now just search all of them at once. ${ }^{32}$ Most federated searching products do offer students the option of searching databases of their own choosing, by exploring subject groupings and sub-groupings and choosing individual databases from a list. Since most do not know what databases we offer or what databases are most appropriate for their research topics, many libraries have opted to offer groupings of pre-selected subject resources or, in an effort to be more like Google, a default group of databases appropriate as a starting point for any research topic. Frank Cervone argues that the subject model may be confusing for students. If they have not yet defined a subject area or if they are conducting interdisciplinary research, "demanding that a subject area be chosen before permitting a search could be a major impediment to effective use of a federated search product." ${ }^{33}$

Students using MetaQuest, Boston College's configuration of MetaLib, are encouraged to begin by conducting a keyword search of 10 of their most popular databases. Included are a number of multidisciplinary databases (Article First, General Reference Center Gold, Expanded Academic ASAP, and Web of Science), some subject-specific resources (Business Source Premier, CINAHL, MLA International Bibliography, and PsycINFO), and Boston College's library catalog. Of all MetaQuest searches, 92 percent take place in these 10 resources. ${ }^{34}$ For their implementation of ENCompass, the 
University of Rochester (UR) chose to offer a search of four default databases (Article First, MLA International Bibliography, Sociological Abstracts, and Wilson OmniFile) in a "find articles" search box. Susan Elliott quotes David Lindahl, Web initiatives manager, as stating that the criteria for choosing these resources were speed, coverage of the range of disciplines at the UR, whether a connector was available, and whether it worked correctly. ${ }^{35}$

Although this solution may assist students in choosing the most appropriate databases, will students actually know what they are searching? Many libraries present students with a search box with no explanation of what databases will be included in their searches. In order to determine what resources are included in a particular QuickSearch category in MetaLib, students must click on the category's hot-linked title. The University of Rochester and Boston College have sought to remedy this by including a link to the list of databases to be searched next to their MetaLib QuickSearch boxes. Studies have yet to be conducted regarding whether students actually utilize these links or have any sense of what databases are included in searches of these categories.

Students searching either the default category or a subject category in a federated searching tool may find the information they need immediately or may use the search for "resource discovery" - determining which databases are best for their research topic, either by overall hit count or number of relevant hits, then conducting a search of those databases individually. There is even some suggestion in the literature that federated search products may foster name recognition of databases for students, causing them to use the native interfaces more than they currently do. ${ }^{36}$ Certainly the implementation of federated searching tools will increase the number and scope of databases students use. The University of Longborough noted a 609 percent increase in the use of resources after a year of implementing MetaLib. ${ }^{37}$ However, if some improvement cannot be made to federated search product interfaces or in product configurations to make students more aware of what databases they are searching, neither resource discovery nor name recognition may be possible. Along with exploring appropriate investigative methods, other outcomes include considering the benefits and applicability of particular methods and the scope, content, and organization of the information retrieval systems. With no recognition of the databases included in a search or some information about them (subject and chronological coverage, for example), students will not be able to achieve this competency.

Of additional concern is the inability of some databases to be included in a federated search. Students may falsely assume that they are searching all the databases the library has in a certain subject area. At Boston College, approximately two-thirds of their $300+$ databases are not MetaQuest-searchable. For example, one of their most popular databases, LexisNexis Academic Universe, cannot be included in their default Quick CrossSearch. These resources can be included in MetaLib and accessed by a link to perform a separate search in its native interface. Boston College librarians "doubt that students are taking the time to go into these resources," and the fact that 92 percent of searches take place in the 10 Quick CrossSearch resources seems to bear them out. ${ }^{38}$ In reporting the results of usability testing at Northwestern and other large universities, Frank Cervone writes, "Patrons, almost exclusively, do not use databases that cannot be part of a federated search from within a federated search interface. They simply ignore them." 39 
Libraries may also choose not to include certain databases for other reasons, including number of simultaneous users or limited seat availability, restrictive licenses, or cost per search. Such restrictions may result in uneven coverage of resources for some disciplines and thus less buy-in from some librarians and faculty. Librarians interviewed by Elliott and McCaskie note restrictions in simultaneously searching databases in nursing, law, and medicine. ${ }^{40}$

Performance indicator 2: The information literate student constructs and implements effectively designed search strategies.

Search sophistication is particularly essential when searching multiple resources. In his observations of students searching MetaQuest at Boston College, Tallent noted their approach was "keyword-based, often just a few terms, sometimes with an understanding of Boolean operators." 41 Showing no apprehension concerning the number of hits that an unfocused search of multiple resources would return, Tallent offers 16 student search examples, none of more than four words.

Some would surmise this was due to the fairly limited search options that federated searching products offer, a symptom of the range of protocols used to search across divergent resources. When describing the search capabilities of these tools, William Frost states, "The default search is by keyword, which is, by the way, the only search metasearching can currently perform." ${ }^{42}$ In point of fact, from MetaLib's advanced search screens, students can combine search terms using Boolean operators and perform limited field searching by subject, title, ISBN, ISSN, and year. Granted, this pales in comparison to the search capabilities of some databases' native interfaces, which permit students to limit their results by source type (peer-reviewed, magazine), content type (bibliography, empirical study), or to use thesauri to discover various disciplines' controlled vocabularies. Due to the lack of sophisticated search features and discipline-specific limits, Terrell believes federated search products do not encourage students to develop sophisticated searching skills. ${ }^{43}$

One should consider, however, whether students' search approaches for federated searching products are any different than for database searching in general. Kate Manuel, in reviewing the literature to determine what first-year students should be taught, lists 15 studies that suggest that "they use unsophisticated searching techniques, which unbeknownst to them are inadequate for finding the needed information." ${ }^{44}$ These studies reveal that the vast majority of students "use simple searches of one or two keywords," and are "unable to use keywords effectively; unwilling to consider synonyms for search terms; unaware of Boolean operators or unskilled at using them; unlikely to search with multiple concepts or with subject headings... or use limits and....advanced features." ${ }^{45}$ Paralleling Terrell's criticism of federated search products, Andrew Williamson attributes these searchers' poor search strategies to their use of Web search engines, the model for these tools, which "tend not to encourage good searching techniques." ${ }^{46}$

Of greater consequence is how individual databases interpret federated searches or, as some have described it, reduce them to the "lowest common denominator." ${ }^{47} \mathrm{~A}$ field search may be handled differently by different resources, and the same field search conducted in a resource from within a federated search portal and its native interface may produce different results. In MetaLib, a phrase search may be interpreted as a phrase, 
an adjacency, or a Boolean AND search, depending on how the resource processes the search request. ${ }^{48}$

One of the outcomes of performance indicator 2 (2.e) is that students "implement the search strategy in various information retrieval systems using different user interfaces and search engines, with different command languages, protocols, and search parameters." 49 Many librarians worry that the "dumbed down" interface of federated search products will replace the need for the more sophisticated native interfaces of individual databases. Vendors of these products, as Peter Webster reports, certainly do not see it this way. They see federated search products "as an enhancement to database-native interfaces, and do not (so far) suggest that they can replace these interfaces." ${ }^{50}$ All federated searching products offer direct links to individual databases, allowing students to explore the native interface of any database with relative ease. They are even proving to be ideal electronic resource management systems, offering additional searching options to find particular databases and replacing the need for a traditional A to $\mathrm{Z}$ database list. Webster concludes, "The most effective search-and-retrieval tools will continue to be the native interfaces provided by database vendors." 51

Performance indicator 3: The information literate student retrieves information online or in person using a variety of methods.

Many federated search products work in tandem with link resolvers. Previously, students looking for a particular article would have to search multiple databases looking for full text or search the title in a journal holdings list. By simply clicking the icon at the end of a bibliographic citation, students can know whether a particular item is accessible. UW-Eau Claire has purchased Ex Libris' SFX. As with any link resolver, SFX “accepts metadata from incoming OpenURLs and compares them to institutional privileges and local holdings to display a menu of links to the appropriate copies of a resource." ${ }^{2}$ This might include a link to the full text of an article from a periodical database, a library catalog record, or an interlibrary loan form. Link resolvers "significantly shorten the cycle for patrons from finding a citation to actually being able to read a resource." ${ }^{53}$ Students will still need to learn classification schemes and the physical location of items within the library in order to find print materials. They will also need advice on user services like interlibrary loan to acquire materials from other libraries.

\section{Standard Three}

Standard three reads: "The information literate student evaluates information and its sources critically and incorporates selected information into his or her knowledge base and value system." ${ }^{54}$ Numerous studies have questioned students' ability to critically evaluate materials found on the Web. ${ }^{55}$ Due to the large number of results that a typical federated search will return, evaluation will become more important than ever before to students in determining which sources to acquire. Much of this evaluation will center on the evaluation of search results.

The results list in many federated searching products is problematic. Depending on the choice of databases or the construction of a category, the results list of a federated search could include a variety of different sources. Federated searching products offer 
little opportunity during the search process to limit results to a specific type of source. The familiar checkbox for peer-reviewed journals, which appears in many databases' native interfaces, is absent from federated searching products. Students whose professors require them to use only peer-reviewed sources will need to use other means to identify these sources. The results list itself cannot be categorized by source type. Some databases, like WorldCat or those offered by ProQuest and EBSCO, offer source tabs at the top of their results lists that may be used to view only magazine articles, for

Due to the large number of results that a typical federated search will return, evaluation will become more important than ever before to students in determining which sources to acquire. example.

As Terrell suggests, students will need to "learn clues about the information sources" to assist them in determining the source type. ${ }^{56}$ Such citation analysis might involve looking for high page numbers or low issue numbers when seeking peer-reviewed journal articles, since such journals are usually continuously paginated and are not generally published more than quarterly. Even if students were to actually acquire such skills, the results summary of some products, compared to the individual database, may frustrate the process. The citation information passed from each database may vary; some may provide the complete citation, whereas others may leave out the abstract or even the volume, issue, and page numbers. Different information may also be displayed depending on the view chosen. In MetaLib, brief view displays the full citation for an item, whereas table view only displays the item's author, title, year, and the database from which it was retrieved. Students may not notice that these options exist.

Librarians may also be able to assist students in the evaluation process. Students rely on librarian decisions regarding not only the configuration of the interface but also in grouping the resources. According to Cervone, "finding the right grouping of databases for 'subject areas' or 'interests' can be a major problem in setting up a federated search engine." 57 Terrell and some of the librarians interviewed by McCaskie advocate for grouping resources not only by subject but also by source coverage, claiming that "federated searching is only appropriate when the same resources are searched." 58 For example, a business $\longrightarrow$ books or a psychology $\longrightarrow$ periodicals category could be created. The downside of this is the number of categories that might be generated. Depending on the databases available in a discipline and their source coverage, this also may not always be possible.

Once students have established the source type of each result, they will need to determine its relevance to their research topic. Relevance ranking may assist students in making informed decisions. In MetaLib, results can be sorted by rank, displayed as a green bar on the left hand side of each result. The more the green bar is filled in, the more relevant the result should be. Paula Hane and others have criticized the reliability of the relevancy rankings in federated searching products. According to Hane, true relevance ranking "basically counts the occurrence of the words being searched in a citation." 59 The greater the occurrence, the higher the relevance. Federated search products only have the citation to work with, rather than the abstract and full text. Relevance-ranking 
algorithms in other resources students may be familiar with, such as the library catalog or Google, also take into account such things as uniqueness of search terms in certain fields or popularity. Google's PageRank, for example, evaluates the pages by counting citations or backlinks to determine the popularity of a particular page as well as text matching. As Tamar Sadeh explains, "Any relevance-ranking algorithm that a metasearch system employs needs to be 'objective' - it must rely on the retrieved document alone, without any knowledge of other documents in the resource from which the document is coming." ${ }^{60}$ Librarians can assign a higher or lower ranking to specific databases in MetaLib to assist in evaluation. This cannot compare, however, to the accuracy of Google PageRank, which is what students will expect from federated searching products.

Students may also gain valuable information from source overlap across the databases, which can be displayed by many federated searching products. When results are retrieved, they are de-duped-duplicates are removed from the results lists, and text is added noting that a result was cited in more than one database. Students may not realize that each database indexes different journals and that some journals may be considered more important than others. One way of introducing this concept is by discussing the significance of the same journal being indexed in multiple databases.

Performance indicator seven describes the information literate student as able to "determine whether the initial query should be revised." 61 Outcomes include reviewing the search strategy pursued and the information retrieval sources used. With its blending of resources and the interpretation of searches across them, students will find it difficult to determine just where they may have erred if or when their results are not meeting their information need. ${ }^{62}$

\section{Standards Four and Five}

Standard four, concerning a student's ability to use information effectively, and standard five, concerning a student's understanding of the economic, legal, and social issues surrounding the use of information, seem to be unaffected by the introduction of federated searching products. Terrell suggests that "the tendency to blur distinctions between information sources could impair understanding of issues regarding legal and ethical use of the information," though disrespect for others' intellectual property and cut-andpaste plagiarism were cited as problems previous to federated search by Miguel Roig. ${ }^{63}$ Students may find the personalization tools of federated searching products, such as the ability to save citations, useful in citing sources and creating bibliographies, an outcome of standard five, performance indicator 2 .

\section{Discussion}

Based on analyses of the standards, it seems obvious that, with proper instruction, federated searching products will not have a significant impact on students' information literacy. McCaskie, who came to the same conclusion, states it thus: "The tool does not make the user more or less information literate; it is the way it is used." 64 If anything, the products will expand students' knowledge of the electronic resources the library offers and encourage greater use of our collections. Librarians, in turn, will need to assist students in using the tool effectively. In doing so, librarians face a number of 
instructional challenges, and what is emphasized in a typical 50-minute instruction session will likely change. Following are predictions of how librarians may begin to adapt their teaching.

- Librarians may no longer need to spend as much time introducing specific research databases for a particular discipline or teaching students how to select the right database. Instead, as many of McCaskie's interviewees pointed out, they will teach students to make distinctions between different types of databases. ${ }^{65}$ Students may be asked to analyze the number of hits returned from each database and the reasons for this.

- Librarians will still teach students how to construct a search strategy. As described by one of McCaskie's interviewees, "The same ideas and strategies are taught searching MetaLib as for other databases and library staff encourages users to think about abbreviations, synonyms, delimiters and generally planning a search strategy."66 Instruction, however, may focus less on teaching students how to search a specific database and more on general searching skills that may be applied to any database. This is not to say that native interfaces will not be taught or used. It may depend on the research level of the student or on the complexity of his/her topic.

- Librarians will spend less time teaching students how to find information and more time teaching them how to use and evaluate it. Students will need to learn more sophisticated techniques in culling results and identifying source types within those results. Terrell hypothesizes that evaluation may move from the more traditional assessment of a bibliographic item's authorship and currency (outcome 2.a of standard three) to an assessment of its content-its logic, strength of argument, and point of view (2.b and c). ${ }^{67}$

Librarians can also configure the interfaces of federated searching products in ways that engender information literacy. Decisions concerning database groupings-whether by subject and by source type or including or not including the library catalog-can assist students in choosing which databases to search. The University of Rochester has chosen not to include the library catalog in their default search, limiting the resources they have included to those databases that index articles. Giovale Library at Westminster College has a separate search box for books and articles in databases. Descriptive help passages can be added where difficulties may arise, like Boston College's explanation of MetaQuest on its entry page or the placement of a link to the list of databases searched under its Quick CrossSearch box to assist students in deciding whether MetaQuest is the tool they should be searching and just what databases in which their search will be conducted. Simple adjustments such as making relevancy/rank or a certain results view the default can assist students with evaluation.

As with any new tool, librarians will also need to create orientation and instructional materials. ${ }^{68}$ These materials can offer a description of and orientation to the tool, searching strategies, and other detailed instruction on how to make the best use of it.

Finally, students from different disciplines and at different learning levels may use the tool differently. Nursing, law, and medicine may not immediately buy into the tool if not enough of the resources in their disciplines may be simultaneously searched. 
Members of a freshman composition class may find everything they need from a search of a default category. Some students may find it particularly useful for interdisciplinary research. Graduate students may utilize the personalization features to create personal database lists to run search alerts. We should not assume that we know how students and other users will use federated searching products. Eight out of 10 librarians surveyed at Research Libraries Group (RLG) libraries that had implemented federated search tools identified undergraduates as the primary audience for metasearch: "We really see this as a tool to help students get started finding stuff-it's not a tool for advanced research. ${ }^{\prime 69}$ Cervone mentions that graduate students and faculty like it because they "find many significant citations they were not previously aware of." 70 Federated search tools offer multiple searching options and levels of complexity that allow students to engage them at their own level.

\section{Conclusion}

Bob Gerrity, Theresa Lyman, and Ed Tallent use the work of Stanley Davis and Christopher Meyer on blur economies as an analogy for what federated searching products represent and why they will, in their opinion, succeed. ${ }^{71}$ Boundaries are being blurred between the academic and commercial Web, between library resources, between the citation and the item itself. Students have no patience with these arbitrary boundaries; they want information, and they want it now, wherever it may be located. Federated searching products seek to increase students' use of our collections by making access both easier and more familiar through the addition of a Google-like interface.

Students will benefit from the introduction of federated search engines in a variety of ways. They will be able to do a broad search of a variety of sources, allowing them an immediate overview of research in their topic area. They will be introduced to databases they may not have known existed. Students conducting interdisciplinary research will be able to search across disciplines. The addition of a link resolver will allow students to quickly and easily locate the information they desire.

Some may argue that the introduction of such tools serves as an impediment to student information literacy. Students will not need to know the most appropriate tool to search for the information they seek nor will they need or be able to construct sophisticated searches. Research shows, however, that students do not know what resources we have nor are they interested in learning

In point of fact, in moving to a more Google-like model for finding information, federated search engines offer librarians more opportunities for instruction. advanced search techniques. As this paper has demonstrated, despite the drawbacks of current federated search technologies, such tools do not have a negative impact on student's information literacy.

Others believe that for federated search tools to be successful they must be able to be used without mediation, thus reducing the need for instruction. In point of fact, in moving to a more Google-like model for finding information, federated search engines offer librarians more opportunities for instruction. These technologies let us 
try different approaches to introduce information literacy concepts to students-both in class and at the reference desk. A fairly simple search of a federated search engine brings with it teachable moments related to what databases are and what sources they include, as well as techniques for evaluation of results. In opposition to the negative impact some have predicted, federated search engines may instead have a positive effect on student information literacy, offering them an entrée into our collections and the research process, while in turn providing us with opportunities to educate them utilizing a tool they will want to use.

Christopher Cox is assistant director of libraries, McIntyre Library, University of Wisconsin-Eau Claire, Eau Claire,WI; he may be contacted via e-mail at: coxcn@uwec.edu.

\section{Notes}

1. Association of College and Research Libraries, "Information Literacy Competency Standards for Higher Education," American Library Association (2000), http:/ / www.ala. org/ala/acrl/acrlstandards/standards.pdf (accessed March 31, 2006).

2. Judy Luther, “Trumping Google: Metasearching's Promise," Library Journal 128, 16 (October 1, 2003): 36-9.

3. Peter Jacso, "Thoughts About Federated Searching," Information Today 21, 9 (October 2004): $17,20$.

4. Susan A. Elliott, "Metasearch and Usability: Toward a Seamless Interface to Library Resources" (August 2004), http:/ / www.lib.uaa.alaska.edu/tundra/msuse1.pdf (accessed March 31, 2006).

5. Paul Ramsden, Learning to Teach in Higher Education (London: Routledge, 1992); Donna Fryer, "Federated Search Engines," Online 28, 2 (March/April 2004): 16-9.

6. Online Computer Library Center, Inc., "OCLC White Paper on the Information Habits of College Students: How Academic Librarians Can Influence Students' Web-Based Information Choices" (June 2002), http:/ / www5.oclc.org/ downloads/ community / informationhabits.pdf (accessed March 31, 2006).

7. Jerilyn Veldof and Karen Beavers, "Going Mental: Tackling Mental Models for the Online Library Tutorials," Research Strategies 18, 1 (2001): 3-20; Barbara J. Cockrell and Elaine Anderson Jayne, "How Do I Find an Article? Insights from a Web Usability Study," Journal of Academic Librarianship 28, 3 (May 2002): 122-32.

8. Roy Tennant, “Five Easy Pieces," Library Journal 129, 19 (November 15, 2004 ): 25.

9. Online Computer Library Center, 9.

10. Joan K. Lippincott, "Net Generation Students \& Libraries," EDUCAUSE Review (March/ April 2005): 56-66; Luther, 36.

11. Barbara Valentine, "The Legitimate Effort in Research Papers: Student Commitment Versus Faculty Expectations," Journal of Academic Librarianship 27, 2 (March 2001): 107-15.

12. Jacso, 17.

13. Ed Tallent, "Metasearching in Boston College Libraries-A Case Study of User Reactions," New Library World 105, 1/2 (2004): 69-75.

14. Wendi Arant and Leila Payne, "The Common User Interface in Academic Libraries: Myth or Reality?" Library Hi Tech 19, 1 (2001): 63-76.

15. Luther, 36.

16. Stanley Wilder, "Information Literacy Makes All the Wrong Assumptions," Chronicle of Higher Education, January 7, 2005, B13.

17. Steven J. Bell, "Submit or Resist: Librarianship in the Age of Google," American Libraries 36, 9 (October 1005): 68-71; Luther, 38-9. 
18. William Frost, "Do We Want or Need Metasearching?" Library Journal 129, 6 (April 1, 2004): 68.

19. Bell, 69 .

20. Devin Zimmerman, “Metasearching's Teaching Moments," Library Journal 129, 14 (September 1, 2004): 54

21. John Terrell, "Cross Database Searching: Information Literacy for the Real World," http:// lifelonglearning.cqu.edu.au/2004 / papers / terrell-133-paper.pdf (accessed March 31, 2006).

22. Lucy McCaskie, "What are the Implications for Information Literacy Training in Higher Education with the Introduction of Federated Search Tools?" (master's thesis, University of Sheffield, 2004), 2.

23. ACRL, 8 .

24. Tallent, 71.

25. Carol. C. Kuhlthau, "Inside the Search Process: Information Seeking from the User's Perspective," Journal of the American Society for Information Science 42, 1 (1991): 361-71.

26. Andrew Cox, “Choosing a Library Portal System," Vine 33, 1 (2003): 37-41.

27. Terrell, 4 .

28. ACRL, 8.

29. Veldof and Beavers; Cockrell and Jayne.

30. Online Computing Library Center, 5.

31. Tallent, 74 .

32. William Baer, "Federated Searching: Friend or Foe," College \& Research Libraries News 65, 9 (October 2004): 518-9.

33. Frank Cervone, "What We've Learned from Doing Usability Testing on OpenURL Resolvers and Federated Search Engines," Computers in Libraries 25, 9 (October 2005): 10-4.

34. Elliott, 77.

35. Ibid., 59 .

36. Baer, 519.

37. Yvonne Hamblin and Ruth Stubbings, "The Implementation of MetaLib and SFX at Longborough University Library," Library and Statistics Unit, Longborough University (October 2003), http: / / www.jisc.ac.uk/ uploaded_documents/Metalibcasestudy.pdf (accessed March 31, 2006).

38. Elliott, 77 .

39. Cervone, $13-4$.

40. Elliott, 21; McCaskie, 60

41. Tallent, 70 .

42. Frost, 68 .

43. Terrell, 5 .

44. Kate Manuel, "What Do First-Year Students Know about Information Research? And What Can We Teach Them?" in Proceedings of the ACRL Twelfth National Conference (Minneapolis, MN: April 7-10, 2005), http:/ / www.ala.org/ala/acrl/acrlevents/manuel05.pdf (accessed March 31, 2006).

45. Manuel, 407.

46. Andrew Williamson, "BUBL Link/5:15: Smarter Than the Average Search Engine," The Serials Librarian 37, 4 (2000): 37-50.

47. Baer, 519.

48. Ex Libris, "User Documentation: MetaLib Version 3.12+ Search Syntax," (November 4, 2004).

49. ACRL,10.

50. Peter Webster, "Metasearching in an Academic Environment," Online 28, 2 (March / April 2004): 20-3.

51. Webster, 22 . 
52. Rachel Frick, Cheri J. Duncan, and William D. Walsh, "Nuts and Bolts of Linking: Understanding Context Sensitive Linking Services and Implementation," The Serials Librarian 48, 3 / 4 (2005): 257-64.

53. Frick, Duncan, and Walsh, 259.

54. ACRL, 11.

55. Manuel, 401.

56. Terrell, 5 .

57. Cervone, 13.

58. McCaskie, 56.

59. Paula J. Hane, "The Truth About Federated Searching," Information Today 20, 9 (October 2003): 24.

60. Tamar Sadeh, "The Challenge of Metasearching," New Library World 105, 3 / 4 (2004): $104-12$.

61. ACRL, 12 .

62. Terrell, 6 .

63. Terrell, 6; Miguel Roig, "Can Undergraduate Students Determine Whether Text Has Been Plagiarized," Psychological Record 47, 1 (1997): 113-22.

64. McCaskie, 66.

65. McCaskie, 64 .

66. McCaskie, 45 .

67. Terrell, 5 .

68. Terrell, 7 .

69. Research Libraries Group, "Report on RLG Metasearch Survey," <http: / / www.rlg.org/ en $/$ page.php?Page_ID=20750\&Printable $=1>($ February 15, 2006).

70. Cervone, 13.

71. Bob Gerrity, Theresa Lyman, and Ed Tallent, "Blurring Services and Resources: Boston College's Implementation of Metalib and SFX," Reference Services Review 30, 3 (2002): 229-441. 